\title{
Versatility of a Nitrogen-Containing Monolithic Porous Carbon for Lithium-Based Energy Storage.
}

\author{
Alvaro Y. Tesio ${ }^{[a] t^{\star}}$, Analía N. Arias ${ }^{[b]}$, Julián Morales ${ }^{[c]}$, Gabriel A. Planes ${ }^{[a]}$, Alvaro Caballero ${ }^{[c]}$.
}

\begin{abstract}
N-containing monolithic porous carbon material with dual micro and mesoporous structures was synthesized using an innovative, cheap and easy synthesis route based on the classical resorcinol-formaldehyde synthesis. A completely chemical, structural and morphological characterization was carried out. The $\mathrm{N}$ content in the carbonaceous material was $7.3 \%$ and XPS data showed that is present in two different surrounds, as $\mathrm{N}$-pyrrolic and $\mathrm{N}$-pyridinic atoms. Is known that, the last one, can acts as a catalyst at surface level in heterogeneous reactions. In addition, using this material, we were able to fabricate lithium-ion and lithium-sulfur batteries obtaining high values of discharge capacity and cycle stability and demonstrating the multifunctional character of this carbon in energy storage devices.
\end{abstract}

\section{Introduction}

The environmental impact of $\mathrm{CO}_{2}$ emissions from internal combustion engines, as well as from coal-fired power plants, combined with a decline in the availability of fossil fuels have created a huge incentive to produce electrical energy from other resources like wind and sun. Considering these energy sources do not provide energy at a constant rate and users need at least a few hours of autonomy, storage systems are starting to play an important role in our lives. However, these applications still do not compete with fossil fuel devices even taking into account the maximum theoretical utilization of the fuel in a combustion engine is close to $40 \%$. ${ }^{[1]}$

In this context, numerous alternatives arise to address the

[a] Dr. A. Y. Tesio , Dr. G. A. Planes

Departamento de Química

Facultad de Ciencias Exactas, Físico-Químicas y Naturales, Universidad Nacional de Río Cuarto

Ruta Nac. 36 Km. 601, Rio Cuarto, Córdoba, Argentina.

E-mail: atesio@cidmeju.unju.edu.ar

[b] Lic. A. N., Arias

Centro de Investigación y Desarrollo en Materiales Avanzados y

Almacenamiento de Energía de Jujuy-CIDMEJu (CONICET-

Universidad Nacional de Jujuy)

Centro de Desarrollo Tecnológico General Savio.

Palpalá, Jujuy, Argentina.

[c] Dr. J. Palomino, Dr. A. Caballero

Departamento de Química Inorgánica

Instituto Universitario de Investigación en Química Fina y Nanoquímica

Campus de Rabanales, Universidad de Córdoba, 14071 Córdoba, España.

Supporting information for this article is given via a link at the end of the document problem. ${ }^{[2]}$ Among these options, lithium-based technologies appear to be prevalent.

What these technologies have in common is the need of having electrodes that allow better performance and, at the same time, its construction combine acceptable costs with availability of raw materials. In addition, all these devices share a fundamental fact, at least one of its components is made of a carbonaceous material, making carbon a key material in the construction of almost all lithium-based technologies.

With the aim of improving energy storage, heteroatom-modified carbons arose as a variant of pure material having attractive results. Among them, one of the most studied is nitrogenfunctionalized carbon.

Numerous articles describe ways to add nitrogen to graphene. Some of them, use in situ chemical polymerization of pyrrole on both surfaces of graphene oxide combined with high temperature carbonization, ${ }^{[3]}$ via chemical activation of polypyrrole-functionalized graphene sheets, ${ }^{[4]}$ or impregnating carbon structures with a nitrogen containing ionic liquid..$^{[5]}$

Other way of functionalizing carbon with nitrogen consist in adding an organic compound (that contains nitrogen) to the carbon matrix, followed by the calcination of these mixed materials. Related to these, nanofibers were obtained from polydopamine with a subsequent template-removing process. ${ }^{[6]}$ Also, ultrafine cobalt sulphide nanoparticles were encapsulated in hierarchical $\mathrm{N}$-doped carbon nanotubes using polyacrylonitrile/cobalt acetate and 2-methylimidazole, followed by the dissolution of the template. ${ }^{[7]}$ On the other hand, $\mathrm{N}$-doped carbon nano-spheres were obtained by mixing dopamine and glucose, through a hydrothermal reaction followed by annealed at $500{ }^{\circ} \mathrm{C} .{ }^{[8]}$ Other nitrogen-rich carbon spheres were prepared by Jaroniec et. al., using a one-pot hydrothermal synthesis in the presence of resorcinol/formaldehyde as carbon precursor and ethylenediamine as both, nitrogen precursor and base catalyst, followed by carbonization and $\mathrm{CO}_{2}$ activation. ${ }^{[9]}$ Finally, it should be mentioned that $\mathrm{N}$-doped activated carbon aerogels with porous structure, derived from sodium alginate, were synthesized by the group of Quan and co-workers. ${ }^{[10]}$

An exception to the multi-step synthesis was reported by Xing et al., who fabricated hollow nanostructured aniline oligomers, generated via a one-step route using copper acetate and phenylenediamine as oxidant and accelerator at room temperature. ${ }^{[11]}$ However, includes one additional step of activation by $\mathrm{HNO}_{3}$ and after that, steps of cleaning, centrifugation and dried in vacuum.

Moreover, in the last years, many $\mathrm{N}$-containing carbon were synthesized, using natural precursors or even waste, such as, cellulose,${ }^{[12]}$ honey, ${ }^{[13]}$ microalgae,${ }^{[14]}$ carps,${ }^{[15]}$ newspapers,${ }^{[16]}$ etc. Different kinds of materials were obtained, and a great variety of techniques were used (activations, templates, several 
steps, etc.). Although the starting materials are cheap, or even waste, the proposed syntheses are not cheap enough.

Because of the low price and the excellent results published in the extended bibliography in the last years, melamine appears as a usual reagent to synthesize $\mathrm{N}$-containing carbon. Different synthesis methods were reported, a lot of them using soft or hard template method, which implies many steps in the process. Almost all of them use a polycondensation of resorcinolformaldehyde introduced by Pekala in the $80^{\circ} .{ }^{[17]}$ Here, melamine acts as a source of nitrogen that begins to form part of the structure during polymerization.

Rao et al., proposed the synthesis of $\mathrm{N}$-doped mesoporous carbon by sol-gel process using a mixture of phenol, formaldehyde and melamine, and Ludox-AS40 (40 wt\% $\left.\mathrm{SiO}_{2}\right)$ as hard template to obtain polymeric gel by prolonged heat treatment at $80^{\circ} \mathrm{C} .^{[18]}$ Meanwhile, the group of László published the synthesis of a mesoporous carbon aerogels with $0-4 \%$ nitrogen content, prepared from 3D resorcinol-melamineformaldehyde aerogels. ${ }^{[19]}$ Zhu et al., fabricated an ordered $\mathrm{N}$ doped mesoporous carbon, through direct self-assembly of resorcinol-melamine-formaldehyde resin adding an amphiphilic triblock co-polymer, without using additional pre-polymerization and hydrothermal solidification steps. ${ }^{[20]} \mathrm{A}$ nitrogen and phosphorus co-doped hierarchically porous carbon has been synthesized by $\mathrm{Yu}$ and co-workers in one-step process, involving the pyrolysis of melamine polyphosphate. ${ }^{[21]}$

Other relevant works, that use melamine, include; production of $\mathrm{N}$-doped carbon networks fabricated in a two-step synthesis, via interfacial dehalogenation of polyvinyl dichloride (PVDC) on 2D CoAl-layered double hydroxide in presence of melamine, ${ }^{[22]} \mathrm{N}$ doped porous carbon obtained from carbon quantum dots and melamine by self-assembly process, ${ }^{[23]}$ and a third one that obtained $\mathrm{N}$-doped carbon materials employing a basic solution of $\mathrm{KOH}$, EDTA and $\mathrm{Ni}\left(\mathrm{NO}_{3}\right)_{2} \cdot 6 \mathrm{H}_{2} \mathrm{O}$ and melamine using a chelated method, followed by calcination and washed with diluted hydrochloric acid, deionized water and ethanol. ${ }^{[24]}$ Notice that, most of these cases involve multi-step synthesis and several and expensive reagents, which is valid from a fundamental point of view. However, from a practical approach, a direct (cheap, one step) synthesis of $\mathrm{N}$-containing porous carbon is required in order to make Li-based technology more affordable.

In the present work, we propose a very easy and inexpensive way to fabricate $\mathrm{N}$-containing carbon $(\mathrm{N}-\mathrm{CC})$ monolith, using a variant of the classical resorcinol-formaldehyde route. Taking the advantage of adding melamine, not only with the aim of incorporating nitrogen to the polymerization, but also with the objective of using it as a "pore forming agent". This is achieved due to the poor solubility of the melamine in our synthesis conditions. The obtained compound was fully characterized and tested as electrode material in Li-S and Li-ion batteries, in order to demonstrate its versatility for energy storage devices.

\section{Results and Discussion}

\section{Characterization}

A scheme of the synthesis reaction is shown in Figure 1. In order to obtain the same structure after each synthesis, and

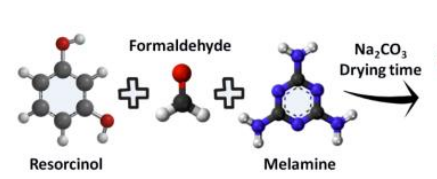

Figure 1. Scheme of the one-step synthesis reaction.

considering that variables like reagents ratio, drying time (previous oven heat), heating ramp and amount of basic catalyst, strongly affect the final morphology and structure, all these parameters were kept fixed.

To understand the thermal behavior of the process and the obtained material, TGA profiles were performed, under nitrogen atmosphere for the precursor mix and in air for the obtained material (Fig. 2). In the case of precursor mix, a great mass loss starts when the temperature reaches $250^{\circ} \mathrm{C}$ and finished $100{ }^{\circ} \mathrm{C}$ beyond, producing a mass decrease close to $75 \%$. This fact is produced by the combination of two processes; condensation and decomposition of the resin and melamine elimination. ${ }^{[25]}$

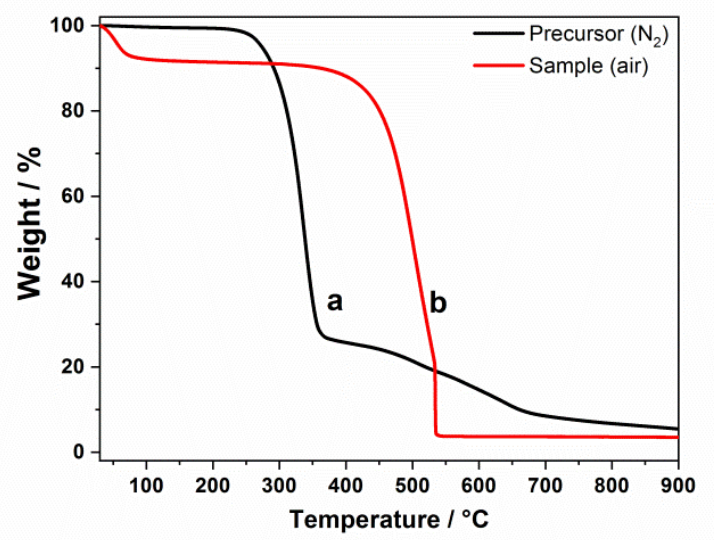

Figure 2. Thermogravimetric analysis of precursor under nitrogen atmosphere (a), and $\mathrm{N}-\mathrm{CC}$ in oxygen (b), heating rate $5^{\circ} \mathrm{C} \mathrm{min}^{-1}$.

Probably at this point of the process, porous structure starts to appear, product of the melamine elimination from inside of a solid matrix carbon, which was occupying a great volume of the initial mass (large excess of melamine respect to resin) and now comes out, leaving a large open space. All the melamine is lost at $360{ }^{\circ} \mathrm{C}$. Finally, between $360{ }^{\circ} \mathrm{C}$ and $700{ }^{\circ} \mathrm{C}$ mass falls to reach a value of $5 \%$ which remains as residue, even up to $900^{\circ} \mathrm{C}$.

On the other hand, when the final product obtained is analyzed in air, a little mass loss from 25 to $400{ }^{\circ} \mathrm{C}$ is observed and can be supposed that it comes from water and carbon dioxide desorption. The relevant data come about $450{ }^{\circ} \mathrm{C}$ with loss of $97 \%$ of the mass, leaving a $3 \%$ that remains until $900{ }^{\circ} \mathrm{C}$, showing that thermal stability of this material, is in agree with previous publications. ${ }^{[20]}$

Due to the presence of melamine during the curing time, and considering its further elimination during the thermal process, it is reasonable to think the resulting material as a highly porous 

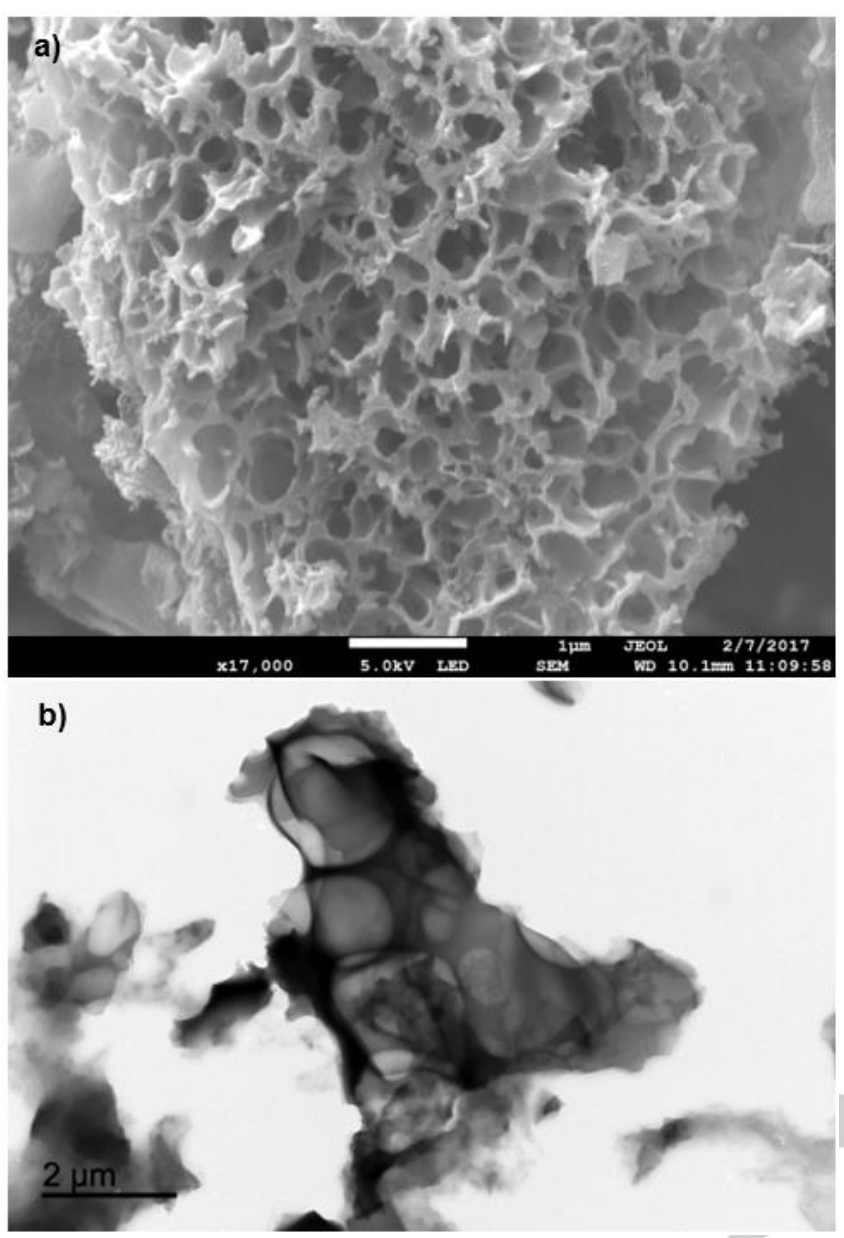

Figure 3. a) SEM and b) TEM images of obtained N-CC.

carbon. This fact is sustained by a fast inspection of SEM and TEM showed in Figure 3a and 3b, respectively. However, should be noted that the observed porous size does not correspond directly with the size of melamine particles (around $30 \mu \mathrm{m}$, as was determined by SEM). The pore size observed in SEM is close to $800 \mathrm{~nm}$, far below the size of the hard template. The origin of such small structure it is not clear, but its presence depends on the thermal pre-treatment (curing) of the sample. While the exposition of the sample during drying/polymerization at low temperature $\left(80^{\circ} \mathrm{C}, 2 \mathrm{~h}\right)$ results in a soft, fragile, and highly porous material as discussed here, sustained exposition to lower temperature $\left(50{ }^{\circ} \mathrm{C}\right)$ results in a hardened and brightly material, in which the small (below $1 \mu \mathrm{m}$ ) size porosity is absent. Instead of the tinny carbon pillars, smooth and bigger carbon walls connect the material across the macropores (see Fig. S.I. 1), resulting in a poor material with low surface area.

Moreover, temperatures above $100{ }^{\circ} \mathrm{C}$ produce a fast loss of water and, probably, a material with a combination of poor polymerization degree, low molecular weight, and low intercrossing between polymer chains. Under these conditions, the polymer structure is weak and easily breaks in small subunits during the high temperature carbonization.

Possibly, the contraction that should take place during polymer densification at $\mathrm{T}<350^{\circ} \mathrm{C}$, it is no allowed by the only existence of the hard template "skeleton" of melamine, giving rise to additional fractures and defects on carbon surface.
As can be seen in the Figure 4 the wide angle XRD patterns shows clearly two peaks, an intense one, around $24.9^{\circ}$ and another (weak peak) close to $43.8^{\circ}$. These two peaks can be assigned to the $\left(\begin{array}{lll}0 & 0 & 2\end{array}\right)$ and $\left(\begin{array}{lll}1 & 0 & 0\end{array}\right)$ crystallographic planes of graphite, respectively.

The low peak intensity/background ratio and the high peak broadening were typical of highly disordered carbons. ${ }^{[26]}$ Notice that, no other crystalline phases are detected in the samples. It should be noted that, no peak was obtained at $2 \theta$ minor than $10^{\circ}$ which indicates that no mesopore ordering was generated (See Fig. S.I. 2.). ${ }^{[27]}$

Complementary to elemental analysis technique, X-ray photoelectron spectroscopy (XPS) technique, was used to confirm the presence of elements in samples, as well as, to investigate what kind of functional groups these elements are part of (Fig. 5). Presence of three elements were detected with peaks centered at $285 \mathrm{eV}$ (C1s), $400 \mathrm{eV}$ (N1s), and $532 \mathrm{eV}$ (O1s), they are in agree with previous reports in comparable materials. ${ }^{[28]}$

C1s peaks region is formed by three different types of carbon. Thus, the mayor carbon signal come from of saturated $\mathrm{sp}^{2}$ graphitic carbon. The other signals can be associated to binding corresponding to $\mathrm{C}-\mathrm{N}$ and $\mathrm{C}-\mathrm{O} .{ }^{[5,29]}$

On the other hand, N1s spectra displays only two peaks, showing the existence of two species of nitrogen, which confirm the incorporation of nitrogen to the carbon matrix, from the unique possible source, melamine. In this case, deconvolution of the multiple peak shows that these two contributions are from pyridinic and pyrrolic nitrogen species, centered at 397.99 and $400.28 \mathrm{eV}$ respectively. Distribution of $\mathrm{N}$-species for the sample were calculated by curve fitting. Values of $62 \%$ and $38 \%$ were obtained respectively. ${ }^{[30]}$

This kind of nitrogen heteroatoms in the graphene layer gives a very interesting property based on the demonstrated additional adsorption capacity. ${ }^{[31]}$ The reason of this behavior lies in the fact that, pyridinic $\mathrm{N}$-atoms have an alone-pair of $\mathrm{p}$-electrons in the plane of the aromatic ring, meanwhile, pyrrolic $\mathrm{N}$-atoms keep its p-electrons as a part of the conjugated p-cloud of the delocalized p-orbitals. ${ }^{[32]}$ Both are $\mathrm{sp}^{2}$ hybridized but, only the first one has the possibility to share these p-electrons with surrounding molecules and acts as a catalyst or preconcentrator site.

A cyclic voltammetry carried out using a piece of this $\mathrm{N}$ functionalized carbonaceous material as a working electrode (Fig. 6a), immersed in $0.1 \mathrm{M} \mathrm{H}_{2} \mathrm{SO}_{4}$, shows a classical capacitive behavior with an increase of capacitance at lower potentials due to a preferential adsorption of cations (in this case, $\mathrm{H}^{+}$). Note that, the quinone/hydroquinone equilibrium is not visible and considering that the electrolyte is a strong acidic medium, this means that, the material was not activated.

When potential is sweep between -0.1 to $1.1 \mathrm{~V}_{\text {NHE }}$ at slow speed $\left(0.001 \mathrm{~V} \mathrm{~s}^{-1}\right)$, capacity current reach a value of $1.75 \mathrm{~mA}$ (at 0.5 $\mathrm{V})$. That means, the capacity of the whole material is $1.75 \mathrm{~F}$, and if we take into account that the used mass of this material was $8.6 \mathrm{mg}$ and also assuming that, graphite capacity is close $15 \mu \mathrm{F}$ $\mathrm{cm}^{-2}$, [33] we can conclude that this carbon has an electroactive area close to $1300 \mathrm{~m}^{2} \mathrm{~g}^{-1}$, or, expressed otherwise, regardless approaches, this carbon has a capacitance of $200 \mathrm{~F} \mathrm{~g}^{-1}$. Which is a very attractive value for these kind of conductive materials. ${ }^{[34]}$ 


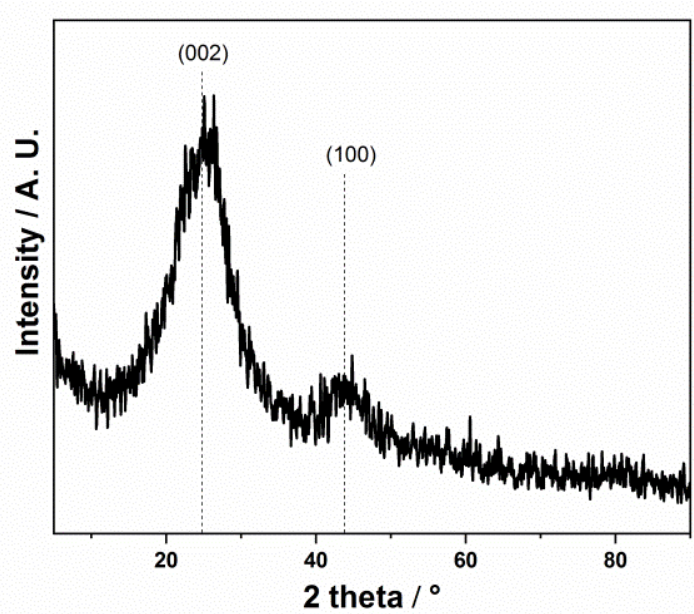

Figure 4. DRX patterns of $\mathrm{N}-\mathrm{CC}$ sample.
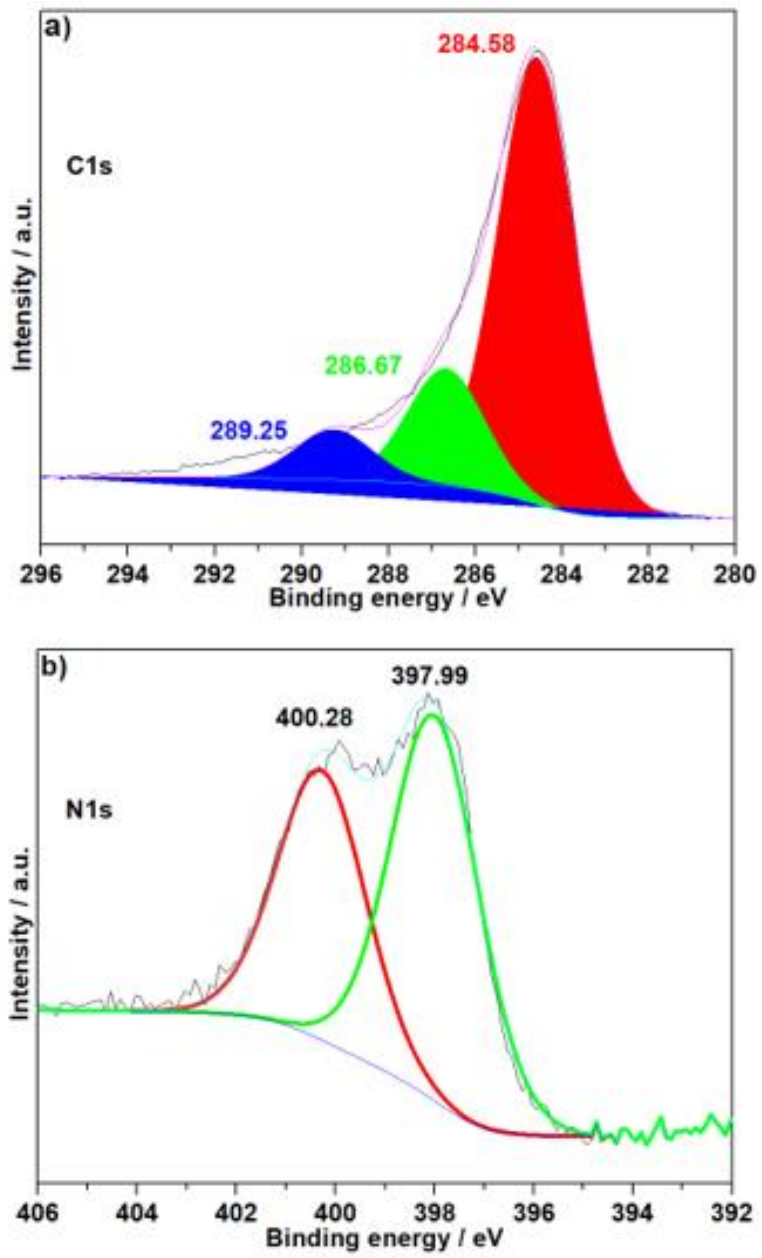

Figure 5. XPS analysis of N-CC sample. Regions: a) carbon b) nitrogen.

Nevertheless, of the value used for surface calculus from the CV, or the model used for surface area determination by $\mathrm{N}_{2}$ adsorption, is evident that the measured capacity is higher when it is compared with other resorcinol-formaldehyde based materials.

Following with the analysis, electrochemical impedance spectroscopy was performed in order to know more about the
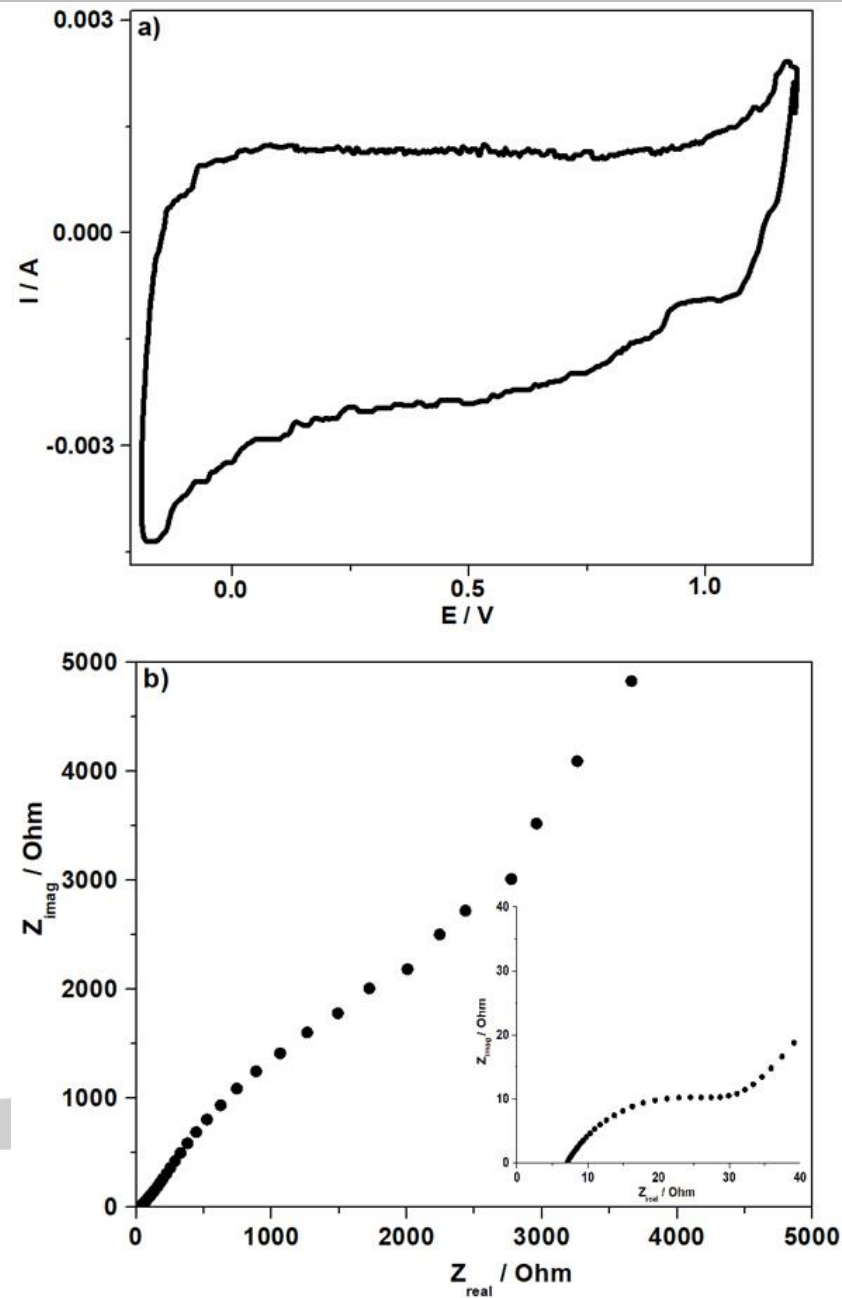

Figure 6. Electrochemistry of a monolithic piece of $\mathrm{N}-\mathrm{CC}$ in $0.1 \mathrm{M} \mathrm{H}_{2} \mathrm{SO}_{4}$. a) Cyclic voltammetry. Scan rate $0.001 \mathrm{~V} \mathrm{~s}^{-1}$. b) Nyquist plot from electrochemical impedance spectroscopy (EIS) data

electrochemical behavior of the material (See Fig. S.I.3 for the equivalent circuit and parameters used). The Nyquist plot in Figure $6 \mathrm{~b}$ shows two semi-circles, corresponding to two different time domains. A faster process is visible at frequencies up to $100000 \mathrm{~Hz}$; and a second one, at lower frequencies (from $50 \mathrm{~Hz}$ to $0.003 \mathrm{~Hz}$ ) is visible in the inset. The first contribution could be assigned to the presence a very accessible surface. Due to the porous nature of the sample, the high frequency response should be associated, in first instance to grain boundary, macropores and (in general) to the geometric surface of the electrode. On the opposite side, the low frequency region includes capacity and resistance values notoriously higher, in addition to a markedly diffusional behavior. In this time-domine, only slow process contributes to the whole impedance, and they are frequently associated to restricted diffusion into micro and macro porosity. ${ }^{[35]}$

In a general scope, the main characteristic of the Nyquist plot in Figure 6 is the prevalence of a diffusional behavior, characterized by a permanent increasing of the real and imaginary part of $Z$. Considering the porous nature of the sample (a monolithic block with size in the millimeter scale) and the high surface area, this response is not surprising. 
Table 1. Summary of electrochemical, morphological and compositional characteristic of the N-CC material obtained.

\begin{tabular}{|c|c|c|c|c|c|c|}
\hline $\begin{array}{l}\mathrm{C}^{\mathrm{a}} \\
\left(\mathrm{F} \mathrm{g}^{-1}\right)\end{array}$ & $\begin{array}{l}\text { Select }^{\mathrm{a}} \\
\left(\mathrm{m}^{2} \mathrm{~g}^{-1}\right)\end{array}$ & $\begin{array}{l}\mathrm{S}_{\mathrm{BET}} \mathrm{b} \\
\left(\mathrm{m}^{2} \mathrm{~g}^{-1}\right)\end{array}$ & $\begin{array}{l}\mathrm{Vt}^{\mathrm{b}} \\
\left(\mathrm{cm}^{3} \mathrm{~g}^{-1}\right)\end{array}$ & $\begin{array}{l}\mathrm{V}_{\mathrm{mi}}{ }^{\mathrm{b}} \\
\left(\mathrm{cm}^{3} \mathrm{~g}^{-1}\right)\end{array}$ & $\begin{array}{l}\mathrm{C}^{\mathrm{c}} \\
(\%)\end{array}$ & $\begin{array}{l}\mathrm{N}^{\mathrm{c}} \\
\text { (\%) }\end{array}$ \\
\hline 204 & 1357 & 309 & 0.308 & 0.121 & 82.5 & 7.3 \\
\hline
\end{tabular}

[a] - Data from cyclic voltammetry. [b] - Data from nitrogen adsorption. [c] Data from elemental analysis.

To examine the porous structure of $\mathrm{N}-\mathrm{CC}$, nitrogen adsorption/desorption isotherms were measured at $77 \mathrm{~K}$.

The shape of the nitrogen adsorption isotherm (Figure 7) displays somewhere in between types I and IV (at high relative pressures) in the Brunauer-Deming-Deming-Teller (BDDT) classification. The observation of a very small hysteresis loop (type $\mathrm{H} 3$ in the IUPAC classification) in the desorption branch is indicative of the presence of slit-shaped pores and/or panel-shaped particles. Pore volume and micro-pore volume are abridged in Table 1 (added with electrochemical obtained values analyzed before). It should to be noted that, the $\mathrm{N}$ contained in the $\mathrm{N}-\mathrm{CC}$ sample (7.3\%, calculated using elemental analysis technique) is a value that is above the average values for $\mathrm{N}$-doped carbon, usually between 3-9 \%, and could be considered as a $\mathrm{N}$-doped carbon with a high $\mathrm{N}$ content. For this reason, we prefer the name of " $\mathrm{N}$ containing carbon" instead of "N-doped carbon".

According to the work of Yan's group, ${ }^{[36]}$ the characterization of porous materials by nitrogen adsorption techniques has several problems when the target material has a high degree of microporosity. Assuming that, only real values were obtained for samples in which, the material does not have a high microstructure. To solve this, similar materials were synthesized, avoiding the evolution of microstructure. Using these materials, values of $64.2 \mathrm{~F} \mathrm{~g}^{-1}$ and $376 \mathrm{~m}^{2} \mathrm{~g}^{-1}$ were calculated from capacity (calculated from electrochemistry) and surface area (calculated from BET), respectively. Based on this information, the values of surface area of $\mathrm{N}-\mathrm{CC}$ sample can be linearly estimated from

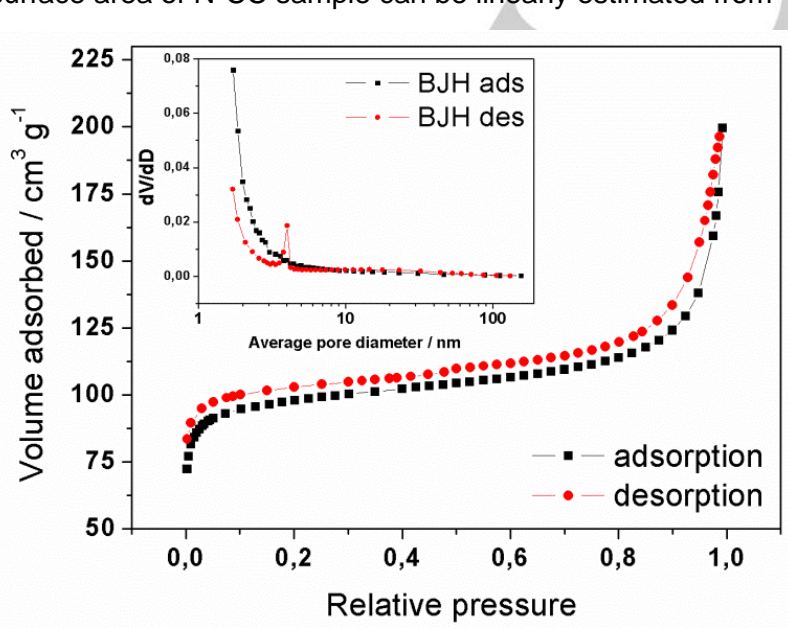

Figure 7. $\mathrm{N}_{2}$ isotherm of $\mathrm{N}-\mathrm{CC}$ sample (inset: pore size calculation using BJH method). electrochemical data, obtaining a value of $1195 \mathrm{~m}^{2} \mathrm{~g}^{-1}$. Value that is close to the one obtained from electrochemical data for electrochemical surface: $1357 \mathrm{~m}^{2} \mathrm{~g}^{-1}$.

\section{Electrochemical test}

$\mathrm{N}-\mathrm{CC}$ was mixed with sulfur powder with the goal to build an advanced Li-S cathode which was examined in a full cell. Figure 8 a show the discharge/charge profile of the composite electrode tested at $0.1 \mathrm{C}$, between 1.7 and $2.7 \mathrm{~V}$ for the second cycle. The characteristic of the discharge curve is the presence of two typical voltage plateaus ascribed to the two-step reaction of $S$ with Li during the discharge process. ${ }^{[37]}$ When charging the cell a strong polarization was observed and the plateaus associated to the two reduction steps are worse defined and overlap, which is consistent with other carbonaceous electrodes previously reported. ${ }^{[27 a]}$

The cycling properties of the N-CC/S composite at $0.1 \mathrm{C}$ rate are shown in Figure 8b. The discharge capacity values vary between 1423, 1287, and $937 \mathrm{mAh} \mathrm{g}^{-1}$ for the first, second, and thirtieth cycles, respectively.

A gradual decrease in the specific capacity of $8.2 \mathrm{mAh} \mathrm{g}^{-1}$ per cycle (barely $6.5 \mathrm{mAh} \mathrm{g}^{-1}$ per cycle when ignoring the first cycle in which the cell is activated) was found, whereas the coulombic efficiency remained at around $98 \%$ after the first few cycles,
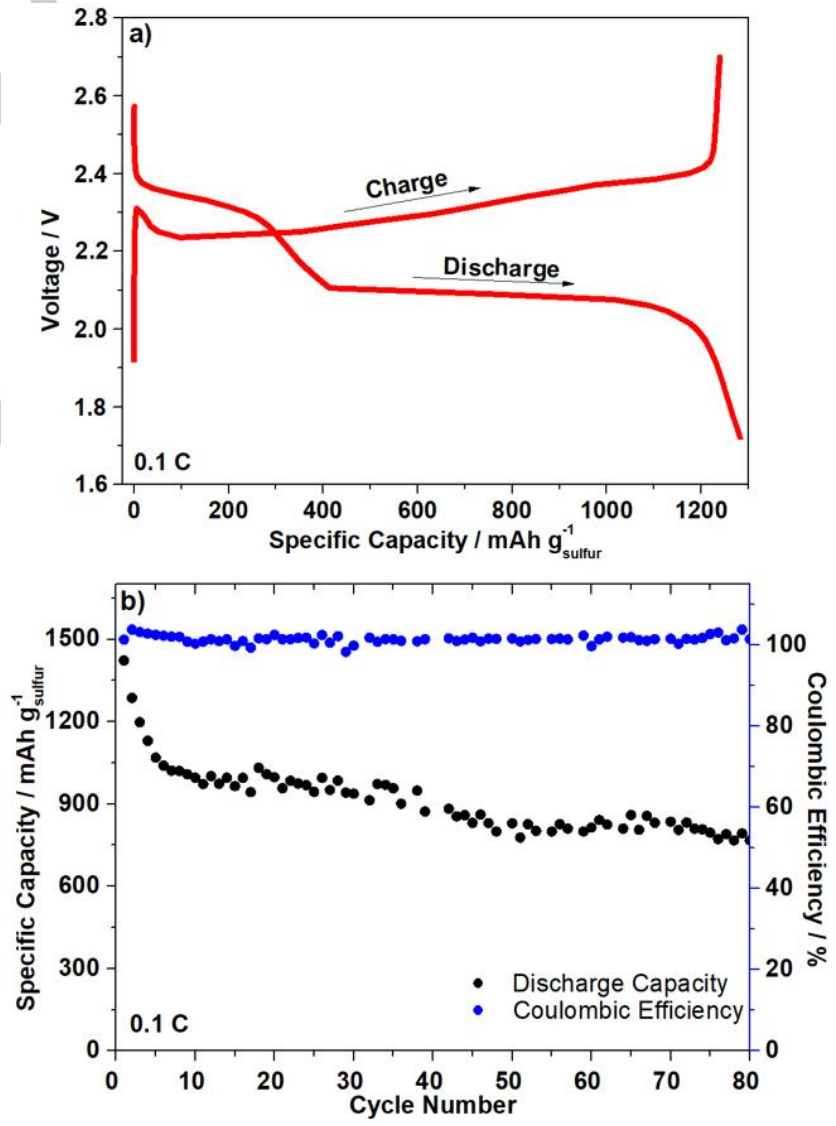

Figure 8. a) Charge/discharge voltage profiles of Li-S battery using a composite made with $\mathrm{N}-\mathrm{CC}$ and sulfur as a cathode material; b) Specific discharge capacity and coulombic efficiencies testing at $0.1 \mathrm{C}$ rate ( $\mathrm{C}$ rate is based on the sulfur theoretical capacity of $1675 \mathrm{mAh} \mathrm{g}^{-1}$ ) 

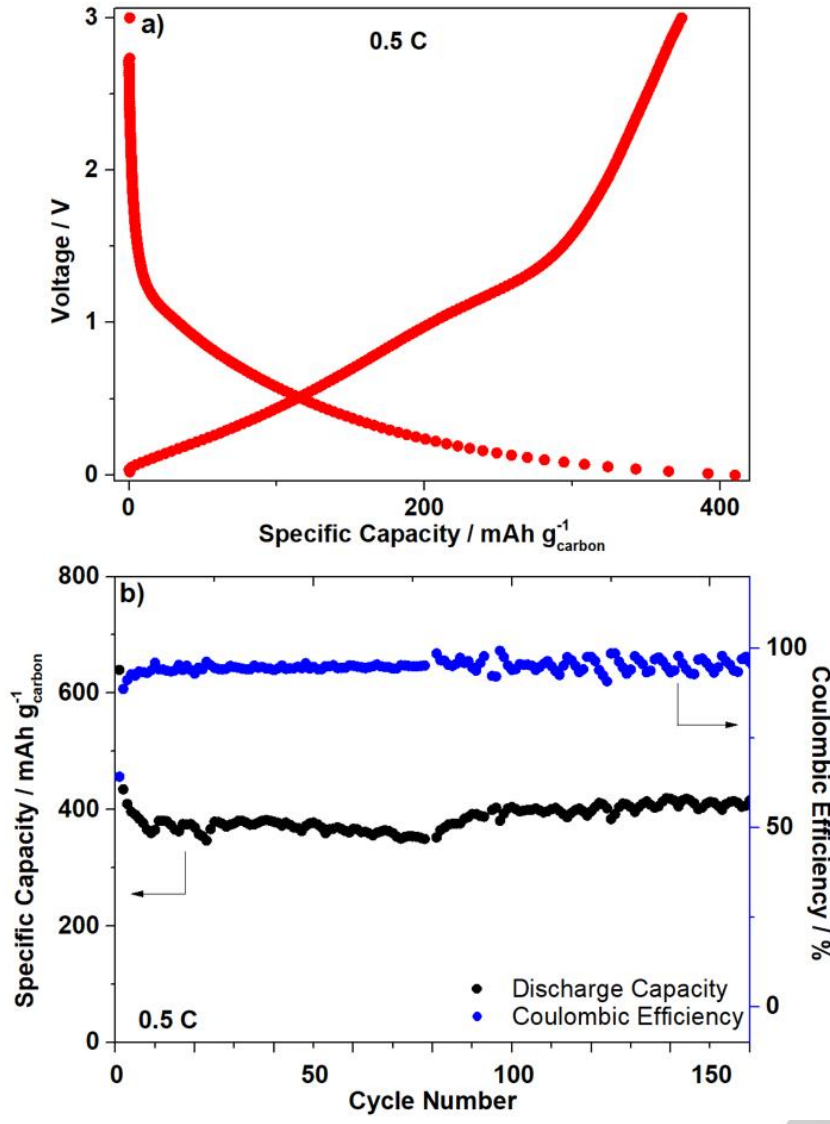

Figure 9. a) Charge/discharge voltage profiles of Li-ion battery using a N-CC as an anode material; b) Specific discharge capacity and coulombic efficiencies in prolonged testing at $0.5 \mathrm{C}$ rate between 0 and $3 \mathrm{~V}(\mathrm{C}$ rate is based on the graphite theoretical capacity of $372 \mathrm{mAh} \mathrm{g}^{-1}$ )

which shows the good cycling stability and high coulombic efficiency of the cell.

These advantages could be due to a possible decrease of the Shuttle polysulphide effect, produced by high nitrogen content in the composite, which successfully hold back soluble products of the electrochemical reactions of sulfur ${ }^{[38]}$ It is clear that, N-CC has the property of binding sulfur-containing species. Pyrrolic $\mathrm{N}$ atoms keep $\mathrm{S}$ atom at the correct place, meanwhile pyridinic $\mathrm{N}$ atoms are responsible for retaining $\mathrm{Li}-\mathrm{S}$ species atom. The high density of delocalized electrons in the $\mathrm{N}$ atoms make these binding possible. ${ }^{[30 \mathrm{~d}]}$

In another set of experiments, to demonstrate the versatility of this material in energy storage devices, N-CC was used as an anode material for half-cell Li-ion battery. Figure 9a shows the third galvanostatic charge-discharge profile of the system between 0 and $3 \mathrm{~V}$ registered at $0.1 \mathrm{C}$ rate.

The charge/discharge profile is typical for this reaction at a low ordered carbon (see Fig. S.I.4 for the first cycle).

After the first normal stabilization cycles, the system reaches a constant value of capacity close to $400 \mathrm{~mA} \mathrm{~h} \mathrm{~g}{ }^{-1}$, which is maintained for more than 150 cycles with a coulombic efficiency around $100 \%$. $(0.027 \%$ per cycle). These results make the material potentially interesting for these technologies (Fig. 9b).

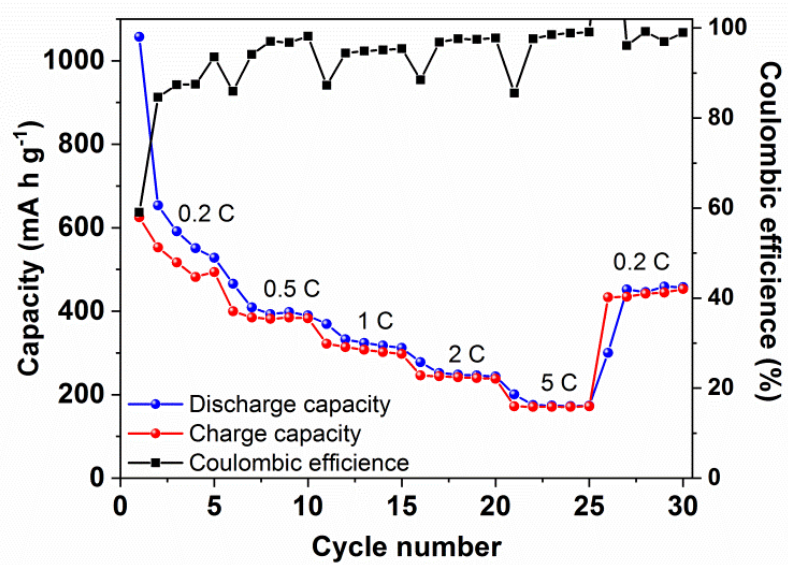

Figure 10. Rate capability of the Li-ion battery using a N-CC as electrode material.

Finally, a rate capability study was carried out in order to know the behavior of the cell at different $C$ values and its reversibility. The results, depict in Figure 10, show a good performance of the cell in these conditions. The remarkable stability of $\mathrm{N}-\mathrm{CC}$ electrode is suggested in Figure 10 by the recovery of $86 \%$ of the initial capacity by lowering back the current to $0.2 \mathrm{C}$ at the 26th cycle.

Overall results indicate the multifunctional character of the synthesized carbon to be used as an electrode in different energy storage systems.

\section{Conclusions}

Through a very simple and inexpensive route, a nitrogencontaining carbon was synthesized. In a fully detailed characterization, material shown several suitable properties to be use as electrode material for energy storage devices. The big value of electrochemical capacitance was one of them; another, the high content of pyridinic atoms. For these reasons, this material was tested as anode in lithium ion batteries and as a cathode in lithium sulfur batteries, the results showed a promising value of capacity and cyclability in both technologies

\section{Supporting Information Summary}

Experimental section, SEM images, XRD pattern, the model using for EIS and complementary characterizations and analysis of NC-C are available in this section.

\section{Acknowledgements}

This work was performed with the financial support of the Ministerio de Economia y Competitividad (Project MAT201459907-R and MAT2017-87541-R), Junta de Andalucía (Group 
FQM-175) and Agencia Nacional de Promoción Científica y Tecnológica (Argentina, Project PICT 2010-2421). A.N.A. have a doctoral fellowship from CONICET which is gratefully acknowledged. AYT thanks to CONICET and to AUIP, specially to the Programa de Becas de Movilidad entre Universidades Andaluzas e lberoamericanas. AYT and GAP are permanent research fellows of CONICET.

Keywords: Energy storage $\cdot$ Lithium batteries $\cdot$ Monolithic $\bullet$ Nitrogen-containing carbon $\bullet$ Sulfur cathodes

[1] J. B. Goodenough, K.-S. Park, Journal of the American Chemical Society 2013, 135, 1167-1176.

[2] D. R. Rolison, J. W. Long, J. C. Lytle, A. E. Fischer, C. P. Rhodes, T. M. McEvoy, M. E. Bourg, A. M. Lubers, Chem Soc Rev 2009, 38, 226-252.

[3] H. Wang, H. Peng, G. Li, K. Chen, Chemical Engineering Journal 2015 , 275, 160-167.

[4] H.-g. Wang, Y. Wang, Y. Li, Y. Wan, Q. Duan, Carbon 2015, 82, 116123.

[5] E.-J. Oh, R. Hempelmann, V. Nica, I. Radev, H. Natter, Journal of Power Sources 2017, 341, 240-249.

[6] W. Xie, L. Gu, S. Li, X. Hou, B. Liu, M. Liu, D. He, Materials Letters 2017, 189, 259-262.

[7] X. Li, N. Fu, J. Zou, X. Zeng, Y. Chen, L. Zhou, W. Lu, H. Huang, Electrochimica Acta 2017, 225, 137-142.

[8] M. Chen, M. Qi, J. Yin, Q. Chen, Materials Research Bulletin 2017, 96 , 335-339.

[9] N. P. Wickramaratne, J. Xu, M. Wang, L. Zhu, L. Dai, M. Jaroniec, Chemistry of Materials 2014, 26, 2820-2828.

[10] J. Zhang, L. Zhang, S. Yang, D. Li, Z. Xie, B. Wang, Y. Xia, F. Quan, Journal of Alloys and Compounds 2017, 701, 256-261.

[11] S. Xing, L. Chen, L. Huang, T. Wang, X. Yu, Y. Zhang, Y. Xing, Synthetic Metals 2017, 227, 170-176.

[12] H. Lu, X. Sun, R. R. Gaddam, N. A. Kumar, X. S. Zhao, Journal of Power Sources 2017, 360, 634-641.

[13] Y. Zhang, L. Chen, Y. Meng, J. Xie, Y. Guo, D. Xiao, Journal of Power Sources 2016, 335, 20-30.

[14] K. S. Lee, M. Park, C. W. Park, J.-D. Kim, Colloids and Surfaces A Physicochemical and Engineering Aspects 2017, 529, 102-106.

[15] R. Wang, H. Song, H. Li, H. Wang, X. Mao, S. Ji, Journal of Power Sources 2015, 278, 213-217.

[16] C.-H. Chang, S.-H. Chung, A. Manthiram, Sustainable Energy \& Fuels 2017, 1, 444-449.

[17] R. W. Pekala, Journal of Materials Science 1989 24, 3221-3227.

[18] M. K. Sahoo, P. Gogoi, G. Rajeshkhanna, S. V. Chilukuri, G. R. Rao Applied Surface Science 2017, 418, 40-48.

[19] B. Nagy, S. Villar-Rodil, J. M. D. Tascón, I. Bakos, K. László, Microporous and Mesoporous Materials 2016, 230, 135-144.

[20] J. Yu, M. Guo, F. Muhammad, A. Wang, G. Yu, H. Ma, G. Zhu, Microporous and Mesoporous Materials 2014, 190, 117-127.

[21] W. Ai, W. Zhou, Z. Du, Y. Chen, Z. Sun, C. Wu, C. Zou, C. Li, W. Huang, T. Yu, Energy Storage Materials 2017, 6, 112-118.

[22] C. Zhang, G. Zhang, H. Li, Y. Chang, Z. Chang, J. Liu, X. Sun, Electrochimica Acta 2017, 247, 1044-1051.

[23] P. Ge, H. Hou, N. Liu, X. Quu, Q. Zeng, C. Wang, L. Shao, X. Ji, Sustainable Energy \& Fuels 2017, 1, 1130-1136.

[24] H. Yuan, W. Zhang, J.-g. Wang, G. Zhou, Z. Zhuang, J. Luo, H. Huang, Y. Gan, C. Liang, Y. Xia, J. Zhang, X. Tao, Energy Storage Materials 2018, 10, 1-9.

[25] Y. Ding, M. B. McKinnon, S. I. Stoliarov, G. Fontaine, S. Bourbigot, Polymer Degradation and Stability 2016, 129, 347-362.

[26] B. Wang, T. P. Ang, A. Borgna, Microporous and Mesoporous Materials 2012, 158, 99-107.

[27] a) N. Moreno, A. Caballero, L. Hernan, J. Morales, J. Canales-Vazquez, Phys Chem Chem Phys 2014, 16, 17332-17340; b) J. Xu, A. Wang, T. Zhang, Carbon 2012, 50, 1807-1816.
[28] a) J. Wei, D. Zhou, Z. Sun, Y. Deng, Y. Xia, D. Zhao, Advanced Functional Materials 2013, 23, 2322-2328; b) Z. Wu, P. A. Webley, D. Zhao, Journal of Materials Chemistry 2012, 22, 11379

[29] H. F. Gorgulho, F. Gonçalves, M. F. R. Pereira, J. L. Figueiredo, Carbon 2009, 47, 2032-2039.

[30] a) N. H. M. Gang Wu, Wei Gao, Shuguo Ma, Ruiqin Zhong, Jiantao Han, Jon K. Baldwin, Piotr Zelenay, ACS Nano 2012, 6, 9764-9776; b) L. Liu, Q.-F. Deng, T.-Y. Ma, X.-Z. Lin, X.-X. Hou, Y.-P. Liu, Z.-Y. Yuan, Journal of Materials Chemistry 2011, 21, 16001; c) Y. Wang, Y. Shao D. W. Matson, J. Li, Y. Lin, ACS Nano 2010, 4, 1790-1798; d) Weidong Zhou, Hao Chen, YingchaoYu, DeliWang, Z. Cui, F. J. DiSalvo, H. D. Abruña, ACS Nano 2013, 7, 8801-8808.

[31] K. Han, J. Shen, S. Hao, H. Ye, C. Wolverton, M. C. Kung, H. H. Kung, ChemSusChem 2014, 7, 2545-2553.

[32] L. Lai, J. R. Potts, D. Zhan, L. Wang, C. K. Poh, C. Tang, H. Gong, Z Shen, J. Lin, R. S. Ruoff, Energy \& Environmental Science 2012, 5 , 7936.

[33] B. E. Conway, Electrochemical Supercapacitors Scientific Fundamentals and Technological Applications, Springer US, 1999.

[34] a) A. Burke, Journal of Power Sources 2000, 91, 37-50; b) A. González, E. Goikolea, J. A. Barrena, R. Mysyk, Renewable and Sustainable Energy Reviews 2016, 58, 1189-1206.

[35] a) G. A. Planes, M. C. Miras, C. A. Barbero, Chemical communications 2005, 2146-2148; b) R. C. Rodriguez, A. B. Moncada, D. F. Acevedo, G. A. Planes, M. C. Miras, C. A. Barbero, Faraday Discussions 2013, 164 147.

[36] X. Wu, J. Zhou, W. Xing, Y. Zhang, P. Bai, B. Xu, S. Zhuo, Q. Xue, Z. Yan, Carbon 2015, 94, 560-567.

[37] N. Moreno, A. Caballero, J. Morales, M. Agostini, J. Hassoun, Materials Chemistry and Physics 2016, 180, 82-88.

[38] a) H.-J. Peng, T.-Z. Hou, Q. Zhang, J.-Q. Huang, X.-B. Cheng, M.-Q. Guo, Z. Yuan, L.-Y. He, F. Wei, Advanced Materials Interfaces 2014, 1 , 1400227; b) J. Song, T. Xu, M. L. Gordin, P. Zhu, D. Lv, Y.-B. Jiang, Y. Chen, Y. Duan, D. Wang, Advanced Functional Materials 2014, 24 1243-1250; c) J. Balach, T. Jaumann, M. Klose, S. Oswald, J. Eckert, L. Giebeler, Journal of Power Sources 2016, 303, 317-324; d) Y. S. Hu, P. Adelhelm, B. M. Smarsly, S. Hore, M. Antonietti, J. Maier, Advanced Functional Materials 2007, 17, 1873-1878. 
Entry for the Table of Contents (Please choose one layout)

Layout 1:

\section{FULL PAPER}

Nitrogen-containing monolithic porous carbon was synthesized via one-step way, using inexpensive raw materials. A completely chemical, structural and morphological characterization was carried out. The obtained carbon has different $\mathrm{N}$-species with a high content of $\mathrm{N}$-pyridinic atoms and a capacitance value of $200 \mathrm{~F} \mathrm{~g}^{-1}$. The material synthesized was used as a cathode in Li-S batteries and as an anode in Li-ion batteries with excellent

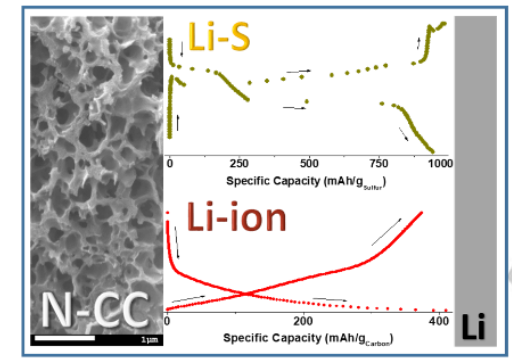

Alvaro Y. Tesio*, Analía N. Arias, Julián Morales, Gabriel A. Planes, Alvaro Caballero.

Page No. - Page No.

Title: Versatility of a NitrogenContaining Monolithic Porous Carbon results.

for Lithium-Based Energy Storage.

Layout 2:

\section{FULL PAPER}

((Insert TOC Graphic here; max. width: $11.5 \mathrm{~cm}$; max. height: $2.5 \mathrm{~cm})$ )

Author(s), Corresponding Author(s)*

Page No. - Page No.

Title

Text for Table of Contents 